\title{
Totally laparoscopic aortobifemoral bypass surgery in the treatment of aortoiliac occlusive disease or abdominal aortic aneurysms - a systematic review and critical
appraisal of literature
}

This article was published in the following Dove Press journal:

Vascular Health and Risk Management

18 May 2017

Number of times this article has been viewed

\author{
Ingeborg Helgetveit ${ }^{1}$ \\ Anne $\mathrm{H} \mathrm{Krog}{ }^{2,3}$ \\ 'Faculty of Medicine, ${ }^{2}$ Institute of \\ Clinical Medicine, University of Oslo, \\ ${ }^{3}$ Department of Vascular Surgery, \\ Division of Cardiovascular and \\ Pulmonary Diseases, Oslo University \\ Hospital, Oslo, Norway
}

Purpose: This systematic review aims to evaluate the published literature regarding totally laparoscopic aortobifemoral bypass (LABF) surgery in the treatment of aortoiliac occlusive disease (AIOD) or abdominal aortic aneurysms (AAA), compared with open aortobifemoral bypass surgery.

Materials and methods: A systematic review of the medical literature between 1990 and 2016 was performed, searching the medical databases Cochrane Library, OVID Medline, Embase and PubMed. Studies concerning totally LABF with or without control group and containing more than 10 patients were included in the analysis. Operative and aortic cross-clamping times, blood loss, rate of conversion to open surgery, mortality and morbidity within the first 30 postoperative days, hospital stay and primary and secondary patency of the graft were extracted and compared with open surgery when possible.

Results: Sixty-six studies were deemed eligible for inclusion in this review, 16 of them matched the inclusion criteria for quantitative synthesis. The patient material consisted of 588 patients undergoing totally LABF, 22 due to AAA, and the remaining 566 for AIOD. Five comparative studies regarding AIOD compared 211 totally LABF procedures with 246 open procedures. Only one study concerning AAA was eligible for inclusion, and this study did not provide a comparison against an open group. The operating and aortic cross-clamping times were shorter in the open group. Conversion rates ranged from $0 \%$ to $27 \%$. There was no statistically significant difference in mortality between the two groups $(p=0.64)$. Hospital stays ranged from 4.0 to 12.1 and 5.0 to 12.8 days in the laparoscopic group and open group, respectively. Most of the studies provided low levels of evidence, mainly due to lack of blinding, randomization and correction of bias.

Conclusion: Totally laparoscopic aortoiliac surgery seems to be a feasible technique with unaffected mortality and trend toward benefits in hospital stay and possibly also in complication rates. The literature published this far is sparse and with inconsistent results. More randomized controlled trials are required before this method can be widely implemented.

Keywords: laparoscopy, aortobifemoral bypass, aortoiliac occlusive disease, aortic aneurysm, aortic disease

\section{Introduction}

The first laparoscopy-assisted aortobifemoral bypass was performed in $1993 .{ }^{1}$ Since the performance of the first totally laparoscopic aortobifemoral bypass (LABF) by the
Correspondence: Ingeborg Helgetveit Faculty of Medicine, University of Oslo, PO Box 1078, Blindern, 0316

Oslo, Norway

Tel +4791706027

Email ingeborg.helgetveit@studmed.uio.no 
same surgeon in $1996,{ }^{2}$ there has been a slow adoption of the technique and few new studies have been performed. Today, 20 years later, open surgery is still considered the standard approach for this procedure but has been lately challenged by the increasingly popular endovascular techniques. However, the endovascular approach shows patency results that seem to be inferior and re-interventions are often required. ${ }^{3}$ Although several studies have shown encouraging results for laparoscopic surgery compared with open surgery, ${ }^{4-6}$ only one relatively small randomized controlled trial (RCT) has been published to date. ${ }^{5}$ Oslo University Hospital is now performing a RCT comparing totally LABF to open aortobifemoral bypass (OABF).

Our review considers patients with severe aortoiliac occlusive disease (AIOD) and/or abdominal aortic aneurysm (AAA) in need of aortobifemoral bypass. Rouhani et al reviewed the perioperative outcomes following laparoscopic AAA repair in $2014,{ }^{7}$ whereas the last systematic review concerning both AIOD and AAA was published in 2008 by Cau et al. ${ }^{8}$ The aim of the present study is to evaluate the level of evidence concerning laparoscopic aortobifemoral surgery compared with the open approach.

\section{Materials and methods Protocol and registration}

The review protocol was published at PROSPERO on January 15,2015 , and is publically available, ID number CRD4 2015016012 .

\section{Eligibility criteria}

This study is a systemic review and a critical appraisal of the published literature from medical databases, from 1990 to 2016. The inclusion and exclusion criteria are given in Table 1.

\section{Information sources and search strategy}

Cochrane, PubMed/Medline and Embase were searched using the following keywords/MESH-terms/all fields: Laparoscop*AND surgery AND aort* including different MESH-terms and synonyms combined by the Boolean

Table I Inclusion and exclusion criteria applied in the evaluation of the eligibility of the articles

\begin{tabular}{|c|c|c|}
\hline & Inclusion criteria & Exclusion criteria \\
\hline Population & $\begin{array}{l}\text { Patients with severe symptomatic AIOD and/or } \\
\text { AAA }\end{array}$ & Non-human subjects \\
\hline Intervention & Totally LABF & $\begin{array}{l}\text { Not total laparoscopic aortic surgery for AIOD and/or AAA treated with } \\
\text { aortobifemoral bypass. For example: } \\
\text { HALS or mini-laparotomy } \\
\text { Laparoscopic surgery for celiac artery compression syndrome } \\
\text { Laparoscopic management of endoleaks after endovascular treatment } \\
\text { Laparoscopic aortorenal or aortomesenteric bypass } \\
\text { The management of vascular injuries during a laparoscopic procedure for a } \\
\text { "non-vascular" condition } \\
\text { Studies reporting procedures other than aortobifemoral bypass and } \\
\text { bifurcated grafts. For example: } \\
\text { Aortounifemoral bypass } \\
\text { Aortoiliac bypass } \\
\text { Use of tube grafts }\end{array}$ \\
\hline Comparison & OABF or no comparison & Anything other than $\mathrm{OABF}$ \\
\hline Outcome & $\begin{array}{l}\text { Mortality } \\
\text { Morbidity and complications }{ }^{\mathrm{a}} \\
\text { Surgical data: operation time and clamping time } \\
\text { Postoperative hospital stay } \\
\text { Primary and secondary patency }\end{array}$ & Not reporting any of the relevant outcomes \\
\hline Study design & $\begin{array}{l}\text { Systematic reviews } \\
\text { Prospective or retrospective patient series with } \\
\text { or without control group } \\
\text { Randomized controlled trials }\end{array}$ & $\begin{array}{l}\text { Case reports } \\
\text { Non-systematic reviews }\end{array}$ \\
\hline Publishing year & $1990-2016$ & Before 1990 \\
\hline Language & English or Norwegian ${ }^{\mathrm{b}}$ & All other languages \\
\hline
\end{tabular}

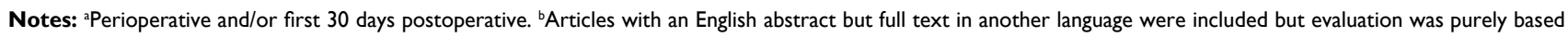
on the abstract. Randomized controlled trials or systematic reviews in languages other than English or Norwegian were translated.

Abbreviations: AIOD, aortoiliac occlusive disease; AAA, abdominal aortic aneurysm; LABF, laparoscopic aortobifemoral bypass; OABF, open aortobifemoral bypass; HALS, hand-assisted laparoscopic surgery. 
variable OR. The full search-strategy is included as a Supplementary material.

The complete search was conducted in January 2015, together with information specialist Hilde Iren Flaatten, Medical University Library, University of Oslo. Before completion of the manuscript, we performed a second literature search with the same search strategy in May 2016 to include new publications from the recent year.

\section{Study selection}

All articles were evaluated for inclusion by two researchers independently (IH and AHK). In case of disagreement, the two researchers discussed the publication based on the inclusion/exclusion criteria previously described. The articles found were at first screened based on title, followed by an assessment of the abstracts of the non-excluded studies. Finally, the full texts of the remaining publications were reviewed, and articles matching all the inclusion criteria were selected for data extraction. This process was repeated for the publications added after the final literature search was performed.

\section{Data collection and data items}

Data were abstracted by one author (IH), and two authors reviewed the final results (IH, AHK). The authors of the different publications were not contacted for additional information regarding methods or results.

We had further exclusion criteria concerning extraction of data from the different articles. As there are few comparative studies published to date, articles lacking a control group were included in the quantitative synthesis. Data were not obtained from studies that included $<10$ patients. Publications presenting clinical research without original patient data were not included in the quantitative analysis; hence, all systematic reviews were excluded from Tables $2-4$. In cases of data published several times, only the latest or largest patient series were considered. This may apply for double publications of the same results, early and mid-time results or subpopulations. All studies containing non-verified double publication of data were included.

We assessed differences in mortality, morbidity, and complications (adverse effects and adverse events [AEs], including but not restricted to, pneumonia, heart attack, paralytic ileus, sepsis, renal failure, cerebrovascular events, bleeding, infection, seroma, major vascular and ischemic events) perioperatively and the first 30 days postoperatively, between those undergoing totally LABF versus OABF. Technical outcomes included operating time, aortic crossclamping time, blood loss, and conversion to open or hand-assisted laparoscopic surgery (HALS). Postoperative outcomes included length of hospital stay and patency rates. Outcome measures of eligible studies were extracted, tabulated, and then analyzed cumulatively using a descriptive statistical approach.

\section{Risk of bias}

All articles included in the data abstraction were evaluated using the "Risk of bias tool" and the "Quality Assessment tool for Quantitative Studies", recommended by the Cochrane Institute. For all major outcomes, the Grading of Recommendations Assessment, Development and Evaluation (GRADE) assessment tool was used to grade the level of evidence and describe our confidence in the result.

\section{Statistics}

Results from studies with prospective or retrospective patient series are presented as comparative tables to assess the safety of the procedure. We used Microsoft Office Excel $2010^{\circ}$ (Microsoft, Redmond Campus, Redmond, Washington, USA) to create the tables. As the data did not allow for a metaanalysis to be performed, the results are narratively reported in the text illustrated with tables. Comparisons between the two treatment groups were performed using the Mann-Whitney $U$-test for continuous variables and Fisher's exact test for categorical variables, if comparison was possible.

\section{Results}

\section{Study selection}

The initial search yielded 983 articles from the different databases. One hundred and ten full-text articles were assessed for eligibility after removal of the studies excluded based on title and abstract, together with duplicates. This resulted in 62 publications matching our inclusion/exclusion criteria, 11 of them concerning robotic surgery.

Our final search, performed on May 13, 2016, resulted in 101 additional articles published over the last year. Four of them met the inclusion criteria and were added to the review, resulting in a total of 66 articles included at last. Due to further exclusion criteria, 50 studies were left out from the quantitative analysis, including six systematic reviews, ${ }^{7-12}$ 25 studies involving $<10$ patients ${ }^{13-37}$ and 19 articles either mixing the results from patients suffering from AIOD and AAA, or not separating patient groups receiving tube grafts and aortounifemoral bypass from the patients receiving aortobifemoral bypass. ${ }^{38-56}$ Hence, 16 articles were deemed eligible for inclusion in Tables 2 and 3, see Figure 1 for details concerning the systematic literature search process for this study. 
Table 2 Aortoiliac occlusive disease

\begin{tabular}{|c|c|c|c|c|c|c|c|c|c|}
\hline $\begin{array}{l}\text { Author and } \\
\text { publication year }\end{array}$ & $\begin{array}{l}\text { Patients } \\
\text { (n) }\end{array}$ & $\begin{array}{l}\text { TASC } \\
\text { group }\end{array}$ & $\begin{array}{l}\text { Operating } \\
\text { time (min) }\end{array}$ & $\begin{array}{l}\text { Clamping } \\
\text { time (min) }\end{array}$ & $\begin{array}{l}\text { Blood loss } \\
(\mathrm{mL})\end{array}$ & $\begin{array}{l}\text { Conversion } \\
\text { rate }(\mathrm{n} \%)\end{array}$ & $\begin{array}{l}\text { 30-day } \\
\text { mortality } \\
(\mathrm{n} \%)\end{array}$ & $\begin{array}{l}\text { 30-day } \\
\text { morbidity } \\
(n)^{\mathrm{e}}\end{array}$ & $\begin{array}{l}\text { Hospital } \\
\text { stay (days) }\end{array}$ \\
\hline Barbera et al, $1998^{61}$ & 11 & NR & 279 & 70 & 563 & $3(27)$ & NR & NR & 10.1 \\
\hline Dion et al, 199966 & 16 & NR & 351 & 107 & 820 & $3(19)$ & 0 & 3 & 7 \\
\hline Dion et al, $1998^{65, a}$ & 10 & NR & 376 & 121 & 820 & $3(33)$ & 0 & 3 & 7.8 \\
\hline Dion et al, $2004^{64, \mathrm{~b}}$ & 40 & B, C, D & 290 & 99 & 497 & $5(10)$ & I (0.025) & 7 & 5 \\
\hline Fourneau et al, $2008^{62}$ & 50 & C, D & 328 & 69 & 600 & II (22) & 0 & 16 & NR \\
\hline Fourneau et al, 2010 $0^{71}$ & 139 & C, D & 250 & 59 & 514 & $19(13.7)$ & $3(2.2)$ & 23 & 5.8 \\
\hline Gracia and Dion, 199967 & 25 & NR & NR & 100 & 820 & $3(12)$ & I $(0.04)$ & NR & 7 \\
\hline Jongkind et al, $201 I^{59, c}$ & 24 & B, C, D & 360 & 113 & 1150 & $4(17)$ & I (0.04) & 4 & 5 \\
\hline Novotny et al, 20I I 58,bc & 19 & C, D & 324 & 68 & NR & I (5) & 0 & NR & NR \\
\hline Remy et al, $2005^{68}$ & 21 & $N R$ & 240 & $60^{d}$ & 500 & I (5) & 0 & $5^{f}$ & 7 \\
\hline
\end{tabular}

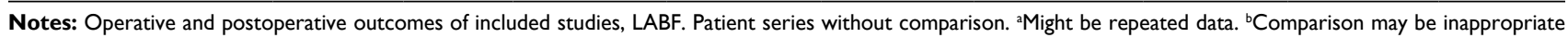
due to different style of reporting the results. 'Robotic surgery. ${ }^{d}$ Reported as time consumed to create the anastomosis, not clamping time. ${ }^{~}$ Number of patients suffering from any systemic or local complication. № intraoperative complications reported.

Abbreviations: LABF, laparoscopic aortobifemoral bypass; TASC, Trans-Atlantic Inter-Society Consensus; NR, not reported

Table 3A Aortoiliac occlusive disease - operative data of included studies, LABF compared with OABF

\begin{tabular}{|c|c|c|c|c|c|c|c|c|c|c|c|c|c|c|}
\hline \multirow{2}{*}{$\begin{array}{l}\text { Author and } \\
\text { publication year }^{\mathrm{a}}\end{array}$} & \multirow[t]{2}{*}{ Randomized } & \multicolumn{2}{|c|}{ Patients (n) } & \multicolumn{2}{|c|}{ TASC group } & \multicolumn{3}{|c|}{ Operating time (min) } & \multicolumn{3}{|c|}{ Clamping time (min) } & \multicolumn{3}{|c|}{ Blood loss (mL) } \\
\hline & & LABF & OABF & LABF & OABF & LABF & OABF & $p$-value & LABF & OABF & $p$-value & LABF & OABF & $p$-value \\
\hline Bruls et al, $2012^{4}$ & No & 95 & 156 & C, D & NR & 242 & 200 & $0.0003^{c}$ & 62 & 33.3 & $<0.0001$ & 682 & 1010 & $<0.0001$ \\
\hline Kazmi et al, $2015^{72, b}$ & No & 50 & 30 & $\mathrm{D}$ & $\mathrm{D}$ & 265 & 214 & 0.0003 & 59.5 & 36.5 & $<0.000$ I & 400 & 1000 & 0.0001 \\
\hline Olinde et al, $2005^{69}$ & No & 22 & 18 & NR & NR & 267 & 180 & NR & 89.5 & 55 & NR & 690 & NR & NR \\
\hline Rouers et al, $2005^{70}$ & No & 30 & 28 & NR & NR & 231 & 136 & $<0.0001$ & 56.8 & 17.2 & $<0.0001$ & $N R$ & NR & NR \\
\hline Tiek et al, $2012^{5}$ & Yes & 14 & 14 & C, D & C, D & 273 & 215 & 0.101 & 48 & 37 & NR & 725 & 982 & 0.28 \\
\hline Total & & 211 & 246 & & & & & & & & & & & \\
\hline
\end{tabular}

Notes: all comparative studies are non-robotic. ${ }^{\mathrm{T} T h i s ~ s t u d y ~ r e p o r t s ~ c o m p o s i t e ~ e n d p o i n t s . ~}{ }^{\mathrm{C}} \mathrm{A}$ different $p$-value $(p=0.10)$ is reported in the article text.

Abbreviations: LABF, laparoscopic aortobifemoral bypass; OABF, open aortobifemoral bypass; TASC, Trans-Atlantic Inter-Society Consensus; NR, not reported.

Table 3B Aortoiliac occlusive disease - postoperative outcomes of included studies, LABF compared with OABF

\begin{tabular}{|c|c|c|c|c|c|c|c|c|c|c|c|}
\hline \multirow{2}{*}{$\begin{array}{l}\text { Author and } \\
\text { publication year }^{\mathrm{a}}\end{array}$} & \multicolumn{2}{|c|}{ Conversion (n\%) } & \multicolumn{3}{|c|}{ 30-day mortality (n\%) } & \multicolumn{3}{|c|}{ 30-day morbidity (n) } & \multicolumn{3}{|c|}{ Hospital stay (days) } \\
\hline & LABF & OABF & LABF & OABF & $p$-value & LABF & OABF & $p$-value & LABF & OABF & $p$-value \\
\hline Bruls et al, $2012^{4}$ & $21(22)$ & & 0 & $3(2)$ & 0.17 & 5 & 40 & $<0.0001$ & 7 & 12.8 & $<0.0001$ \\
\hline Kazmi et al, $2015^{72, b}$ & $7(14)$ & & c & c & & d & d & & 5 & 11 & 0.0001 \\
\hline Olinde et al, $2005^{69}$ & $2(9)$ & & I (4.5) & 0 & NR & 5 & 4 & NR & 4 & 5 & $N R$ \\
\hline Rouers et al, $2005^{70}$ & $6(2)$ & & 0 & 0 & & 12 & 14 & NR & 12.1 & 11.5 & $<0.0001$ \\
\hline Tiek et al, $2012^{5}$ & 0 & & 0 & 0 & & $\mathrm{I}^{\mathrm{e}}$ & $7^{e}$ & NR & 4.5 & 9.5 & 0.0095 \\
\hline Total & $36(17)$ & & I & 3 & $0.64^{f}$ & & & & & & \\
\hline
\end{tabular}

Notes: ${ }^{a}$ All comparative studies are non-robotic. ${ }^{b}$ This study reports composite endpoints. ${ }^{c}$ This study reports total mortality and morbidity at the end of the study and could not be included in the comparison of mortality between the two groups. ${ }^{\mathrm{d}}$ The study reports number of systemic complications and graft thrombosis altogether at the end of the study. ${ }^{e}$ No major complications in either group, only minor. ${ }^{~}$ Note that the study by Kazmi et al ${ }^{72}$ could not be included in the calculation.

Abbreviations: LABF, laparoscopic aortobifemoral bypass; OABF, open aortobifemoral bypass; NR, not reported.

An unsystematic search performed after the final search made us aware of two more studies. One regarded the long-term results of totally LABF, ${ }^{6}$ whereas the other study by Krog et a ${ }^{57}$ concerned the acute phase response after laparoscopic versus OABF surgery. They were not systematically reviewed and hence left out from the analysis.

\section{Study characteristics}

This systematic review comprises 66 articles; six systematic reviews, one RCT, six comparative studies, and 53 cohort studies. Finally, 16 studies were deemed eligible for inclusion in the quantitative synthesis, two of them concerning robotic surgery $^{58,59}$ and one AAA surgery. ${ }^{60}$ 
Table 4 Summary of findings table and grading the level of evidence of the results from the comparative studies ${ }^{\mathrm{a}}$

\begin{tabular}{|c|c|c|c|c|c|}
\hline \multirow[t]{2}{*}{ Outcomes } & \multicolumn{2}{|l|}{ Comparison } & \multirow{2}{*}{$\begin{array}{l}\text { Number } \\
\text { of studies }\end{array}$} & \multirow{2}{*}{$\begin{array}{l}\text { Quality of evidence } \\
\text { (GRADE) }\end{array}$} & \multirow[t]{2}{*}{ Comments } \\
\hline & LABF & OABF & & & \\
\hline Operating time & Range $23 \mathrm{I}-273$ minutes & Range $136-215$ minutes & 5 & $\begin{array}{l}\text { Low }^{b, c, d} \\
(\bullet \bullet \circ))\end{array}$ & $p<0.05$ in three studies \\
\hline Clamping time & Range $48-89.5$ minutes & Range $17.2-55$ minutes & 5 & $\begin{array}{l}\text { Low }{ }^{b, c, e} \\
(\bullet \bullet \circ \circ)\end{array}$ & $p<0.05$ in three studies \\
\hline Blood loss & Range $400-725 \mathrm{~mL}$ & Range $982-1010 \mathrm{~mL}$ & 4 & $\begin{array}{l}\text { Low }{ }^{b, c, f} \\
(\bullet \bullet \circ \circ)\end{array}$ & $p<0.05$ in two studies \\
\hline Hospital stay & Range 4-12.I days & Range $5-12.8$ days & 5 & $\begin{array}{l}\text { Low }^{b, c, d} \\
(\bullet \bullet \circ \circ)\end{array}$ & $p<0.05$ in four studies \\
\hline Morbidity/complications & Range 5-12 complications & Range $4-40$ complications & 4 & $\begin{array}{l}\text { Very low } w^{b, c, g} \\
(\bullet \circ \circ))\end{array}$ & Uncertain effect estimates \\
\hline Mortality & $0 \%-4.5 \%$ & $0 \%-2 \%$ & 4 & $\begin{array}{l}\text { Low }{ }^{b, c, h} \\
(\bullet \bullet \circ \circ)\end{array}$ & No significant differences \\
\hline
\end{tabular}

Notes: GRADE Working Group grades quality of evidence. Every closed circle indicates the level of evidence from very low quality to high quality. High quality: further research is very unlikely to change our confidence in the estimate of effect. Moderate quality: further research is likely to have an important impact on our confidence in the estimate of effect and may change the estimate. Low quality: further research is very likely to have an important impact on our confidence in the estimate of effect and is likely to change the estimate. Very low quality: we are uncertain about the estimation. ${ }^{\text {a }}$ Studies lacking a control group were not included in the SoF table. ${ }^{b} A l l$ but one study were observational studies. 'Weak effect estimates. All studies report range values, no studies reported confidence intervals. ${ }^{\mathrm{d}} \mathrm{One}$ study did not report $p$-values. ${ }^{69}{ }^{\mathrm{e}} \mathrm{Two}$ studies did not report $p$-values. ${ }^{5,69}$ T Two studies did not report $p$-values. ${ }^{69,70} \mathrm{~g} / \mathrm{mprecision}$ of results. Great diversity in the kind of complications reported. Only one study reported p-value. ${ }^{4}$ 'One study did not report $p$-value. ${ }^{69}$

Abbreviations: GRADE, Grading of Recommendations Assessment, Development and Evaluation; LABF, laparoscopic aortobifemoral bypass; OABF, open aortobifemoral bypass; SoF, summary of findings.

The publication years ranged from 1997 to 2016 . The last addition was a prospective comparative cohort study using propensity score matching in order to diminish bias. ${ }^{56}$ The sample size ranged from $11^{61}$ to 139 patients $^{62}$ in the intervention group, the equivalent numbers for the open control group were $14^{5}$ to $156^{4}$ patients. Most patients were classified as $\mathrm{C}$ or D according to the Trans-Atlantic Inter-Society Consensus (TASC) classification, ${ }^{63}$ with two publications also including TASC B lesions. ${ }^{59,64}$ Seven articles did not report the TASC classification of the included patients..$^{61,65-70}$

\section{Peri- and postoperative outcomes}

A total of 588 patients underwent totally LABF surgery, 566 for AIOD and 22 due to AAA. Of the 566 patients undergoing LABF surgery for AIOD, 211 of them were included in the five comparative studies and compared with 246 open procedures for AIOD that served as the control group. The different outcomes after LABF surgery for AIOD are reported in Tables 2 and 3.

Due to inconsistency in the use of mean and median between the publications, the results from the studies are reported individually in Tables 2 and 3. No summary or combining the results was possible, making the planned meta-analysis inappropriate.

\section{Laparoscopic surgery due to AIOD without control group}

Overall, the operating time ranged from $240^{68}$ to $376 \mathrm{~min}-$ utes $^{65}$ in the 10 cohorts concerning AIOD, ${ }^{58,59,61,62,6468,71}$ with aortic cross-clamping time ranging from $59^{71}$ to 121 minutes (Table 2) ${ }^{65}$ The perioperative blood loss ranged from $497^{64}$ to $1150^{59} \mathrm{~mL}$. Between $5 \%{ }^{64}$ and $27 \%{ }^{61}$ of the procedures resulted in conversion to open surgery or HALS. The overall mortality in this group was low; a total of six patients died (1.7\%). The study by Barbera et al did not report 30-day mortality ${ }^{61}$ The morbidity range was quite consistent between the studies, ranging from $16 \%$ to $18 \%$. Three studies reported slightly higher rates of $32 \%,{ }^{62} 33 \%{ }^{65}$ and $23.8 \%{ }^{68}$ Length of hospital stay was reported by eight studies ${ }^{59,61,64-68,71}$ and ranged from $5^{64}$ to $10.1^{61}$ days. In terms of patency, the different studies demonstrated large variation in follow-up times. Consequently, this outcome was not included in Table 2.

\section{Comparative studies concerning AIOD}

Further information is included in Table 3A. Five of the studies were comparative in nature, ${ }^{4,5,69-72}$ including one $\mathrm{RCT}^{5}$ In the laparoscopic group, the operating time ranged from a mean of 231 minutes $^{70}$ to a median of 273 minutes, ${ }^{5}$ and the aortic cross-clamping time stretched from a median of 48 minutes $^{5}$ to a median of 89.5 minutes. ${ }^{69}$ Both mean/ median operating and clamping times were shorter for all the open procedures. Three publications found the difference in operating and cross-clamping time between the laparoscopic and open group to be statistically significant. ${ }^{4,70-72}$ Two studies did not report $p$-values. ${ }^{5,69}$

A median blood loss of $400 \mathrm{~mL}^{72}$ was reported as the lowest for the laparoscopic group, with a median of $725 \mathrm{~mL}^{5}$ being the most substantial amount of hemorrhage occurring. In the 


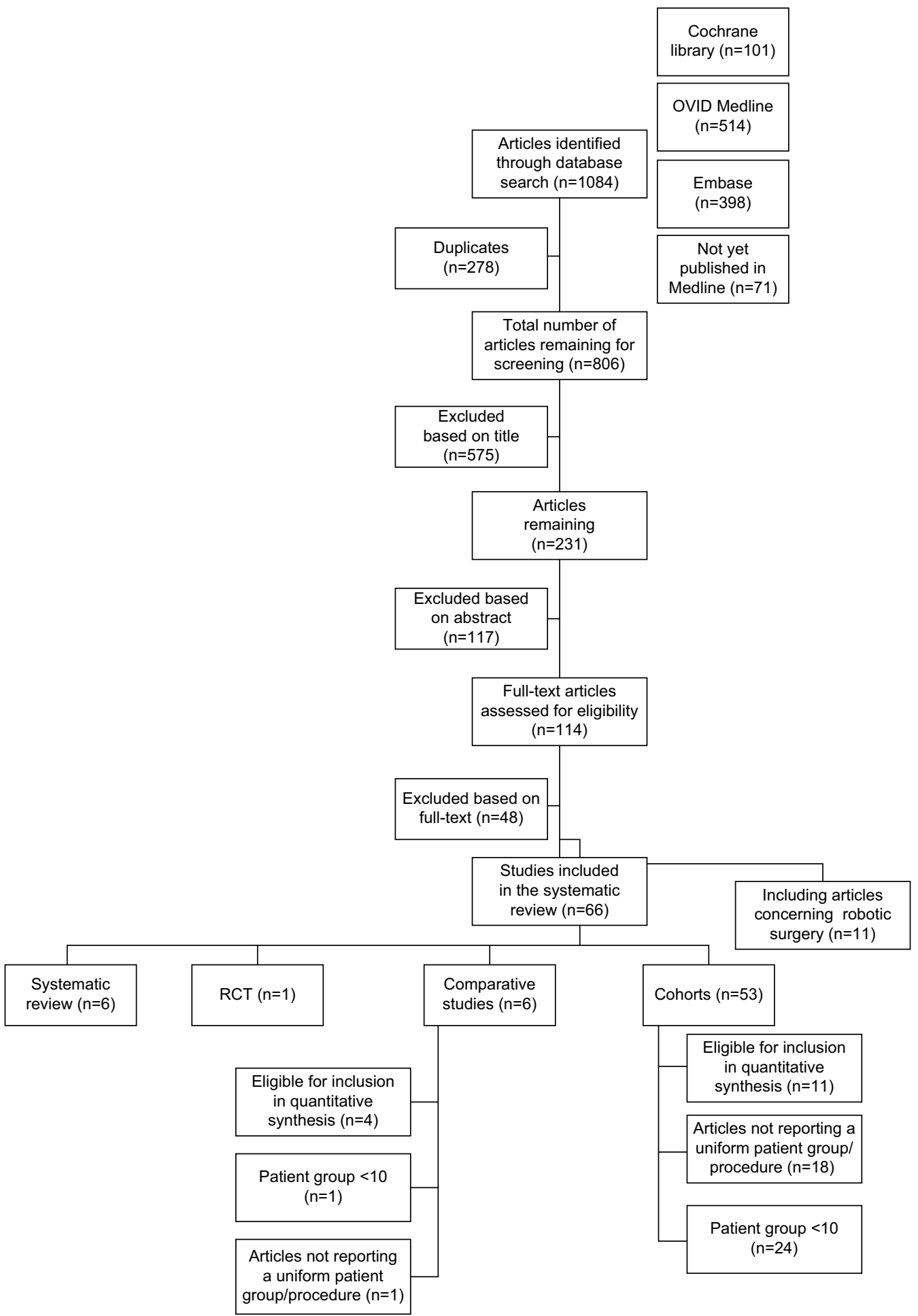

Figure I Flow chart of systematic search for literature and inclusion regarding laparoscopic aortobifemoral bypass surgery compared with open aortobifemoral bypass. Notes: A total of 66 articles met the inclusion criteria. Sixteen of them were also eligible for inclusion in quantitative synthesis.

Abbreviation: RCT, randomized controlled trial.

open group, the blood loss ranged from $982^{5}$ to $1010 \mathrm{~mL} .^{4}$ One study did not report this outcome at all..$^{70}$ Two studies found the difference between the two groups to be statistically significant, ${ }^{4,72}$ two did not report $p$-values, ${ }^{69,70}$ and in one paper, the difference did not reach statistical significance. ${ }^{5}$
Numbers regarding conversion rate, mortality, morbidity and length of hospital stay are reported in Table 3B. The conversion rate in the laparoscopic group ranged from $2 \%{ }^{70}$ to $22 \% .{ }^{4}$ One research group was able to perform all the procedures without need for conversion. ${ }^{5}$ However, this 
publication presented the smallest patient group, with only 14 patients in the laparoscopic group.

Regarding mortality, three studies in the laparoscopic group $p^{4,5,70}$ and three in the open group ${ }^{5,69,70}$ reported a mortality rate of zero. None of the findings were significant. In contrast, significant differences in mortality between the two groups were obtained by Kazmi et al, ${ }^{72}$ reporting a $p$-value of 0.005 in favor of less mortality in the laparoscopic group. However, the latter study reported the total mortality at the end of the study, and not after 30 days.

We calculated the difference in mortality between the open and laparoscopic groups (Table 3B). We found no significant differences in mortality between the two groups $(p=0.64)$. For the reasons pointed out above, the study by Kazmi et al ${ }^{72}$ could not be included in this calculation.

The morbidity rate displayed a wide range in both groups. One study found this difference to be statistically significant, with higher morbidity in the open group. ${ }^{4}$

The shortest length of hospital stay was a median of 4 days in the laparoscopic group and 5 days following open surgery, both outcomes originating from the same study. ${ }^{69}$ The longest duration of hospital stay after surgery was a mean of 12.1 days in the laparoscopic group and 12.8 days in the open group. ${ }^{4}$ This difference was found to be statistically significant in all studies. One study did not report $p$-value for this outcome. ${ }^{69}$

Not all publications described patency rates, and the studies displayed great diversity in follow-up time and the patency definition. Hence, this was left out from Table 3A and B.

\section{AAA repair}

Only one study concerning AAA surgery was included in the quantitative synthesis ${ }^{60}$ and included 22 patients. All patients underwent laparoscopic surgery, and the study did not include a comparison with any open procedures. The rest of the studies concerning AAA were excluded from the quantitative synthesis as a consequence of either small patient series or because the results were reported together for AAA and AIOD. Originating from one study, these outcomes are not reported in Tables 2-4. Edoga et $\mathrm{a}^{60}$ reported an operating time of 391 minutes and a clamping time of 146 minutes. Blood loss was not an outcome. Two of the 22 procedures $(9 \%)$ were converted to open surgery, both of them due to difficulty in exposure of the aorta. Two patients died from myocardial infarction and multiorgan failure, respectively. They were both high-risk patients enrolled early in the trial before the introduction of a global risk assessment scoring system. Nine patients (41\%) developed perioperative complications, most of them suffering from transient postoperative ileus. The average length of hospital stay was 6.2 days.

\section{Methodological quality}

Of the 16 studies included in the quantitative synthesis, only one of them was randomized. ${ }^{5}$ One publication attempted to correct for bias, making use of a propensity score matching system. ${ }^{73}$ As this article reported the results together for aortobifemoral bypass and other procedures applying tube graft, it was not eligible for inclusion in the quantitative analysis.

After evaluating the quality of the individual articles using Risk of bias tool recommended by the Cochrane Institute, only the RCT was rated as "strong", 5 two as "moderate" 65,68 and the rest as "weak". The systematic reviews were evaluated similarly and also displayed variable quality. Three studies were assessed to be of low methodological quality, ${ }^{8,9,11}$ two of moderate quality ${ }^{7,10}$ and one of high quality, with a satisfactory methodological chapter. ${ }^{12}$

The GRADE approach was applied to assess our confidence in the results (Table 4). The quality of evidence was low for all outcomes, largely due to study design and weak effect estimates.

\section{Discussion}

In this review, we have seen that totally LABF for AIOD seems to achieve satisfactory results compared with OABF, with shorter hospital stay, longer operating and clamping times and perhaps less peri- and postoperative complications in the laparoscopic group. The overall research conducted so far provides a low level of evidence and is clearly focused on AIOD surgery. Hence, no conclusions could be drawn regarding AAA surgery.

An international consensus for the management of peripheral disease was updated in $2007,{ }^{74}$ recommending aortobifemoral bypass as the procedure of choice for most patients with severe (TASC C or D) AIOD. Despite several studies demonstrating the feasibility of totally laparoscopic aortic surgery, ${ }^{38,42,47,55,61,65,68}$ the widespread use of this technique has remained relatively low. A rapid development of endovascular methods has led to few centers adopting the procedure.

This review demonstrates that the quality of the research and evidence is low, with great diversity between the studies and their way of reporting results. Heterogeneity of the studies and selection of the patients made comparison difficult. Nevertheless, it seems quite evident that laparoscopic surgery for AIOD is related to longer operating and clamping times, with three of the comparative studies 
showing $p$-values $<0.05$ for this result. Similarly, significant differences were obtained by four studies in favor of shorter hospital stay in the laparoscopic group, leading us to believe that laparoscopic surgery might result in a shorter postoperative course. This may have an impact on decision making and health economy. ${ }^{70,75}$

The results regarding intraoperative blood loss and postoperative morbidity were less conclusive, but there is a tendency toward less postoperative complications in the laparoscopic group. Morbidity was defined differently by the research groups and made comparison unfortunate. However, significantly shorter hospital stay in the laparoscopic group can be a result of fewer intra- and postoperative complications, and possibly less intraoperative blood loss in the laparoscopic group, as both these outcomes are indirect measures of intraoperative problems encountered. ${ }^{75-77}$ The two studies that did report $p$-values for differences in morbidity ${ }^{4,72}$ had the largest patient groups of all the studies. Kazmi et $\mathrm{al}^{72}$ reported results over a period of 6 years and included a thorough analysis of the complications faced. From these results, it seems possible that less morbidity comes at the expense of longer operating and clamping times.

Overall, most studies provide evidence that laparoscopic surgery for AIOD is comparable with open surgery in terms of survival and safety of the procedure. This is in great contrast to the only study reporting negative results so far. The latest study by Ricco et $\mathrm{al}^{73}$ suggests that the laparoscopic approach significantly increases the risk of AE compared with open surgery. However, the study combines the results of aortobifemoral bypass surgery for AAA and AIOD and hence was not included in the quantitative synthesis. Combined results from the two patient groups must be interpreted cautiously. In the study by Edoga at al, ${ }^{60}$ the operating and clamping time was notably longer than all the laparoscopic surgeries performed for AIOD. A complication rate of $41 \%$ was reported. Conclusions cannot be drawn on the basis of one study alone. Nevertheless, it seems that laparoscopic surgery for AAA involves longer operating and clamping times, ${ }^{8,78}$ thus, perhaps, resulting in more complications than surgery performed for AIOD. Similar observations have been made after comparing open surgery for AAA and AIOD, with increased risk of death in the AAA group. ${ }^{79}$

Ricco's cohort study ${ }^{73}$ attempts to reduce the recruitment bias by using propensity score matching, a method originally introduced by Rosenbaum and Rubin. ${ }^{80}$ This approach is meant to limit selection bias by predicting the likelihood that a patient with given characteristics will receive a specific treatment. In this particular study, 50 patients from the laparoscopy group were matched with 50 patients from the laparotomy group and showed similar scores. Both the propensity score matched group and the overall series found significantly higher risk of AE after undergoing LABF compared with OABF. Although this study could not be included in our final analysis, it still brings a few new and noteworthy points into the discussion. The publication is interesting for more than one reason.

On the one hand, higher probability for AE in the laparoscopic group has not previously been reported. However, the study has composite endpoints, grouping together different AEs such as death, postoperative hemorrhage, myocardial infarction, stroke, postoperative respiratory failure and problems related to the prosthesis and anastomosis. A similar method was applied by Kazmi et al. ${ }^{72}$ Employing composite endpoints in the analysis is a way of generating significant results in smaller patient series but may pose interpretation difficulties, as an increased risk for the individual events may be related to each other and impose very different clinical importance. In contrast to Ricco's publication, ${ }^{73}$ Kazmi et al ${ }^{72}$ found significantly less morbidity in the laparoscopic group even by means of a composite endpoint, an outcome more similar to previous publications.

On the other hand, propensity score matching has been criticized and errors are often made when applying this method in statistical analysis. ${ }^{81}$ Without knowing the full implication this might have, it is worth mentioning that medical complications were balanced out between LABF and OABF in this particular study. This might imply that the risk of AE following LABF is closely linked to surgical technique, particularly completion of the anastomosis. The complexity of the procedure is indicated by a considerable learning curve ${ }^{68}$ which is overcome after $\sim 25-30$ procedures. ${ }^{62}$ Lately, robots have been used in an attempt to shorten the operating time by assisting in the creation of the anastomosis. So far, it seems to be a viable technique, ${ }^{50}$ which may enhance the surgical procedure. ${ }^{9,59}$ There is a distinct need for further research concerning robotic laparoscopic surgery.

\section{Limitations}

This systematic review has several limitations, mostly due to poor quality of the individual studies and great diversity in terms of procedure type and reporting manners. A metaanalysis could not be performed and the results could not be summarized, as there was no uniformity in the way they were described. Few publications reported standard deviations as part of their analysis, and even less studies made use of $p$-values when comparing with other groups. Consequently, range became the most objective measurement of reporting the results. Unfortunately, this is substantially less reliable than performing a meta-analysis. Some of the publications 
seem to report repeated patient material. Nevertheless, all the mentioned studies were included, as this assumption could not be verified. What impact this has on the results can hardly be quantified.

In addition to the problems encountered above, numerous studies reported diverse patient and procedure groups, and the larger part of the studies were excluded from the quantitative synthesis for this reason. These studies carry a significant risk of bias, assuming operating and clamping times are considerably longer for AAA than AIOD, ${ }^{8,78}$ and vary between the procedure types. Most of Stadler's publications ${ }^{45,46,48,51,52}$ were affected by this decision and could not be included despite a large patient material in most of the studies. This was one of the main reasons why most of the studies concerning AAA surgery could not be included.

Most studies were observational, and the description of the characteristics of the consecutive patients in the cohorts was inadequate in most of them. We must assume a considerable selection bias, as none of the studies describe attempts to correct confounders existing in the different groups. The only randomized study was closed prematurely at 28 patients, ${ }^{5}$ when an ethical committee eventually found it unethical to randomize patients originally referred for laparoscopic surgery. As a consequence of weak study designs and low methodological quality resulting from the limitations described above, the research conducted this far provides evidence of low quality. This is emphasized by the quality assessment of both the individual studies (Risk of bias tool) and the outcome results from all the studies grouped together (GRADE). When assessing the latter, the GRADE approach was applied. Although this grading system is widely accepted ${ }^{82,83}$ and recommended by the Cochrane Institute, the weak effect estimates and reporting manners provided by all the studies included in this review made full utilization of the method difficult.

\section{Conclusion}

The laparoscopic aortoiliac surgery is still sparsely employed despite promising results for AIOD. No research comparing totally laparoscopic surgery for AAA with open surgery, without combining results from $\mathrm{AIOD}$, has been conducted to date. It seems reasonable to claim that $\mathrm{LABF}$ can be performed safely, with shorter hospital stay, less intraoperative hemorrhage, and possibly less peri- and postoperative complications and morbidity compared to open surgery. Open surgery delivers shorter operating and aortic crossclamping times. The mortality rate appears unaffected by surgical approach. However, few centers and surgeons are performing this procedure. The published literature to date is of weak quality and the level of evidence is low. There is a need for further research.

\section{Acknowledgments}

All expenses for this review were covered fully by the University of Oslo. We extend a very special thanks to late Prof Jørgen J Jørgensen for all the inspiration, guidance and support. We also thank medical librarian Hilde Iren Flaatten at the University of Oslo for her contribution with the literature search and Dr. Truls Erik B Johansen at the Department of Urology, Oslo University Hospital, for helpful advice and critical revision.

\section{Author contributions}

All authors contributed toward data analysis, drafting and revising the paper and agree to be accountable for all aspects of the work.

\section{Disclosure}

The authors report no conflicts of interest in this work.

\section{References}

1. Dion YM, Katkhouda N, Rouleau C, Aucoin A. Laparoscopy-assisted aortobifemoral bypass. Surg Laparosc Endosc. 1993;3(5):425-429.

2. Dion YM, Gracia CR, Demalsy JC. Laparoscopic aortic surgery. JVasc Surg. 1996;23(3):539.

3. Timaran CH, Prault TL, Stevens SL, Freeman MB, Goldman MH. Iliac artery stenting versus surgical reconstruction for TASC (TransAtlantic Inter-Society Consensus) type B and type C iliac lesions. J Vasc Surg. 2003;38(2):272-278.

4. Bruls S, Quaniers J, Tromme P, Lavigne JP, Van Damme H, Defraigne JO. Comparison of laparoscopic and open aortobifemoral bypass in the treatment of aortoiliac disease. Results of a contemporary series (2003-2009). Acta Chir Belg. 2012;112(1):51-58.

5. Tiek J, Remy P, Sabbe T, et al. Laparoscopic versus open approach for aortobifemoral bypass for severe aorto-iliac occlusive disease - a multicentre randomised controlled trial. Eur J Vasc Endovasc Surg. 2012;43(6):711-715.

6. Lecot F, Sabbe T, Houthoofd S, Daenens K, Fourneau I. Long-term results of totally laparoscopic aortobifemoral bypass. Eur JVasc Endovasc Surg. 2016;52(5):581-587.

7. Rouhani MJ, Thapar A, Maruthappu M, Munster AB, Davies AH, Shalhoub J. Systematic review of perioperative outcomes following laparoscopic abdominal aortic aneurysm repair. Vascular. 2015;23(5): 525-553.

8. Cau J, Ricco JB, Corpataux JM. Laparoscopic aortic surgery: techniques and results. J Vasc Surg. 2008;48(6 Suppl):37S-44S; discussion 45S.

9. Antoniou GA, Riga CV, Mayer EK, Cheshire NJ, Bicknell CD. Clinical applications of robotic technology in vascular and endovascular surgery. J Vasc Surg. 2011;53(2):493-499.

10. Economopoulos KP, Martinou E, Hakimian S, et al. An overview of laparoscopic techniques in abdominal aortic aneurysm repair. $J$ Vasc Surg. 2013;58(2):512-520.

11. Lin JC. The role of robotic surgical system in the management of vascular disease. Ann Vasc Surg. 2013;27(7):976-983.

12. Nio D, Diks J, Bemelman WA, Wisselink W, Legemate DA. Laparoscopic vascular surgery: a systematic review. Eur JVasc Endovasc Surg. 2007;33(3):263-271. 
13. Dion YM, Gracia CR. A new technique for laparoscopic aortobifemoral grafting in occlusive aortoiliac disease. JVasc Surg. 1997;26(4):685-692.

14. Said S, Mall J, Peter F, Muller JM. Laparoscopic aortofemoral bypass grafting: human cadaveric and initial clinical experiences. JVasc Surg. 1999;29(4):639-648.

15. Alimi YS, Hartung O, Orsoni P, Juhan C. Abdominal aortic laparoscopic surgery: retroperitoneal or transperitoneal approach? Eur JVasc Endovasc Surg. 2000;19(1):21-26.

16. Alimi YS, Hartung O, Valerio N, Juhan C. Laparoscopic aortoiliac surgery for aneurysm and occlusive disease: when should a minilaparotomy be performed? J Vasc Surg. 2001;33(3):469-475.

17. Wisselink W, Cuesta MA, Gracia C, Rauwerda JA. Robot-assisted laparoscopic aortobifemoral bypass for aortoiliac occlusive disease: a report of two cases. J Vasc Surg. 2002;36(5):1079-1082.

18. Dion YM, Thaveau F, Fearn SJ. Current modifications to totally laparoscopic "apron technique". J Vasc Surg. 2003;38(2):403-406.

19. Coggia M, Javerliat I, Di Centa I, et al. Total laparoscopic infrarenal aortic aneurysm repair: preliminary results. JVasc Surg. 2004;40(3):448-454.

20. Desgranges P, Bourriez A, Javerliat I, et al. Robotically assisted aortofemoral bypass grafting: lessons learned from our initial experience. Eur J Vasc Endovasc Surg. 2004;27(5):507-511.

21. Mercier O, Coggia M, Javerliat I, Di Centa I, Colacchio G, GoeauBrissonniere O. Total laparoscopic repeat aortic surgery. J Vasc Surg. 2004;40(4):822-825.

22. Coggia M, Di Centa I, Javerliat I, Alfonsi P, Kitzis M, GoeauBrissonniere OA. Total laparoscopic abdominal aortic aneurysms repair. J Cardiovasc Surg (Torino). 2005;46(4):407-414.

23. Nio D, Diks J, Linsen MA, et al. Robot-assisted laparoscopic aortobifemoral bypass for aortoiliac occlusive disease: early clinical experience. Eur J Vasc Endovasc Surg. 2005;29(6):586-590.

24. Ruurda JP, Draaisma WA, van Hillegersberg R, et al. Robot-assisted endoscopic surgery: a four-year single-center experience. Dig Surg. 2005; 22(5):313-320.

25. Di Centa I, Coggia M, Javerliat I, et al. Total laparoscopic suprarenal aortic coral reef removal. J Vasc Surg. 2006;44(1):194-197.

26. Kazmi SS, Sundhagen JO, Florenes TL, Kroese AJ, Jorgensen JJ. Laparoscopic aortic surgery. Tidsskr Nor Laegeforen. 2007;127(11): $1518-1520$

27. Coggia M, Cerceau P, DiCenta I, Javerliat I, Colacchio G, GoeauBrissonniere O. Total laparoscopic juxtarenal abdominal aortic aneurysm repair. J Vasc Surg. 2008;48(1):37-42.

28. Debing E, De Brabandere K, Vanhulle A, Van Den Brande P. From retroperitoneoscopic lumbar sympathectomy to total laparoscopic abdominal aorta surgery: how to learn. J Cardiovasc Surg (Torino). 2008;49(4): 511-517.

29. Di Centa I, Coggia M, Cochennec F, Alfonsi P, Javerliat I, GoeauBrissonniere O. Laparoscopic abdominal aortic aneurysm repair in octogenarians. J Vasc Surg. 2009;49(5):1135-1139.

30. Di Centa I, Coggia M, Cochennec F, Javerliat I, Alfonsi P, GoeauBrissonniere O. Total laparoscopic repair of abdominal aortic aneurysm with short proximal necks. Ann Vasc Surg. 2009;23(1):43-48.

31. Lee T, Kim HH, Han HS, Min SK, Ha J, Kim SJ. Early experiences of laparoscopic aortofemoral bypass in Korea-report from a single center. Ann Vasc Dis. 2009;2(1):34-39.

32. Lin JC, Kaul SA, Rogers CG. Successful total robotic-assisted aortobifemoral bypass for treatment of complicated aortoiliac occlusive disease. Vasc Endovascular Surg. 2011;45(4):340-344.

33. Fukui S, Alberti V, Mallios A, Soury P, Gigou F. Early and mid-term results of total laparoscopic bypass for aortoiliac occlusive lesions. J Cardiovasc Surg (Torino). 2012;53(2):235-239.

34. Lin JC, Kaul SA, Bhandari A, Peterson EL, Peabody JO, Menon M. Robotic-assisted aortic surgery with and without minilaparotomy for complicated occlusive disease and aneurysm. J Vasc Surg. 2012;55(1):16-22.

35. Guo LR, GuYQ, Qi LX, et al. Totally laparoscopic bypass surgery for aortoiliac occlusive disease in China. Chin Med J. 2013;126(16):3069-3072.
36. Qi L, Gu Y, Guo L, et al. Analysis of operation-related complications of totally laparoscopic aortoiliac surgery. Chin Med J. 2014;127(7): 1218-1221.

37. Howard AQ, Bennett PC, Ahmad I, Choksy SA, Mackenzie SI, Backhouse CM. Introduction of laparoscopic abdominal aortic aneurysm repair. Br J Surg. 2015;102(4):368-374.

38. Coggia M, Javerliat I, Di Centa I, et al. Total laparoscopic bypass for aortoiliac occlusive lesions: 93-case experience. J Vasc Surg. 2004;40(5): 899-906.

39. Kolvenbach R, Schwierz E, Wasilljew S, Miloud A, Puerschel A, Pinter L. Total laparoscopically and robotically assisted aortic aneurysm surgery: a critical evaluation. J Vasc Surg. 2004;39(4):771-776.

40. Coggia M, Javerliat I, Di Centa I, et al. Total laparoscopic versus conventional abdominal aortic aneurysm repair: a case-control study. J Vasc Surg. 2005;42(5):906-910; discussion 911.

41. Lin JC, Kolvenbach R, Schwierz E, Wassiljew S. Total laparoscopic aortofemoral bypass as a routine procedure for the treatment of aortoiliac occlusive disease. Vascular. 2005;13(2):80-83.

42. Cau J, Ricco JB, Marchand C, et al. Total laparoscopic aortic repair for occlusive and aneurysmal disease: first 95 cases. Eur J Vasc Endovasc Surg. 2006;31(6):567-574.

43. Dooner J, Lee S, Griswold W, Kuechler P. Laparoscopic aortic reconstruction: early experience. Am J Surg. 2006;191(5):691-695.

44. Kolvenbach R. Total laparoscopic aortic aneurysm surgery. Acta Chir Belg. 2006;106(1):36-39.

45. Stadler P, Matous P, Vitasek P, Spacek M. Robot-assisted aortoiliac reconstruction: a review of 30 cases. JVasc Surg. 2006;44(5):915-919.

46. Stadler P, Sebesta P, Vitasek P, Matous P, El Samman K. A modified technique of transperitoneal direct approach for totally laparoscopic aortoiliac surgery. Eur J Vasc Endovasc Surg. 2006;32(3):266-269.

47. Di Centa I, Coggia M, Cerceau P, et al. Total laparoscopic aortobifemoral bypass: short- and middle-term results. Ann Vasc Surg. 2008; 22(2):227-232.

48. Stadler P, Dvoracek L, Vitasek P, Matous P. Is robotic surgery appropriate for vascular procedures? Report of 100 aortoiliac cases. Eur J Vasc Endovasc Surg. 2008;36(4):401-404.

49. Coscas R, Coggia M, Di Centa I, Javerliat I, Cochennec F, GoeauBrissonniere O. Laparoscopic aortic surgery in obese patients. Ann Vasc Surg. 2009;23(6):717-721.

50. Stadler P. Role of the robot in totally laparoscopic aortic repair for occlusive and aneurysmal disease. Acta Chir Belg. 2009;109(3):300-305.

51. Stadler P, Dvoracek L, Vitasek P, Matous P. Robotic vascular surgery, 150 cases. Int J Med Robot. 2010;6(4):394-398.

52. Stadler P, Dvoracek L, Vitasek P, MatouAi P. The application of robotic surgery in vascular medicine. Innovations (Phila). 2012;7(4):247-253.

53. Javerliat I, Capdevila C, Beauchet A, Di Centa I, Goeau-Brissonniere O, Coggia M. Results of laparoscopic surgery for abdominal aortic aneurysms in patients with standard surgical risk and anatomic criteria compatible with EVAR. Ann Vasc Surg. 2013;27(4):412-417.

54. Coscas R, Maumias T, Capdevila C, Javerliat I, Goeau-Brissonniere $\mathrm{O}$, Coggia M. Mini-invasive treatment of abdominal aortic aneurysms: current roles of endovascular, laparoscopic, and open techniques. Ann Vasc Surg. 2014;28(1):123-131.

55. Ghammad K, Dupuis A, Amond L, et al. Total laparoscopic bypass is safe and effective for aortoiliac occlusive disease. J Vasc Surg. 2015; 61(3):698-702.

56. Ricco JB, Cau J, Biancari F, et al. Outcome after open and laparoscopic aortic surgery in matched cohorts using propensity score matching. Eur J Vasc Endovasc Surg. 2016; 52(2):179-188.

57. Krog AH, Sahba M, Pettersen EM, et al. Comparison of the acute-phase response after laparoscopic versus open aortobifemoral bypass surgery: a substudy of a randomized controlled trial. Vasc Health Risk Manag. 2016;12:371-378.

58. Novotny T, Dvorak M, Staffa R. The learning curve of robot-assisted laparoscopic aortofemoral bypass grafting for aortoiliac occlusive disease. J Vasc Surg. 2011;53(2):414-420. 
59. Jongkind V, Diks J, Yeung KK, Cuesta MA, Wisselink W. Mid-term results of robot-assisted laparoscopic surgery for aortoiliac occlusive disease. Vascular. 2011;19(1):1-7.

60. Edoga JK, James KV, Resnikoff M, Asgarian K, Singh D, Romanelli J. Laparoscopic aortic aneurysm resection. J Endovasc Surg. 1998;5(4): 335-344.

61. Barbera L, Mumme A, Metin S, Zumtobel V, Kemen M. Operative results and outcome of twenty-four totally laparoscopic vascular procedures for aortoiliac occlusive disease. JVasc Surg. 1998;28(1):136-142.

62. Fourneau I, Lerut P, Sabbe T, Houthoofd S, Daenens K, Nevelsteen A The learning curve of totally laparoscopic aortobifemoral bypass for occlusive disease. How many cases and how safe? Eur JVasc Endovasc Surg. 2008;35(6):723-729.

63. Norgren L, Hiatt WR, Dormandy JA, Nehler MR, Harris KA, Fowkes FGR. Inter-society consensus for the management of peripheral arterial disease (TASC II). J Vasc Surg. 2007;45(1 Suppl):S5-S67.

64. Dion YM, Griselli F, Douville Y, Langis P. Early and mid-term results of totally laparoscopic surgery for aortoiliac disease: lessons learned. Surg Laparosc Endosc Percutan Tech. 2004;14(6):328-334.

65. Dion YM, Gracia CR, Estakhri M, et al. Totally laparoscopic aortobifemoral bypass: a review of 10 patients. Surg Laparosc Endosc. 1998; 8(3):165-170.

66. Dion YM, Cardon A, Hartung O, Gracia CR. Laparoscopic aorto-iliac surgery: present status and future perspectives. Surg Technol Int. 1999; 8:201-207.

67. Gracia CR, Dion YM. Technological advances in laparoscopic aortoocclusive surgery. Semin Laparosc Surg. 1999;6(3):164-174.

68. Remy P, Deprez AF, D'Hont C, Lavigne JP, Massin H. Total laparoscopic aortobifemoral bypass. Eur J Vasc Endovasc Surg. 2005;29(1): $22-27$.

69. Olinde AJ, McNeil JW, Sam A, Hebert SA, Frusha JD. Totally laparoscopic aortobifemoral bypass: a review of 22 cases. JVasc Surg. 2005;42(1):27-34

70. Rouers A, Meurisse N, Lavigne JP, et al. Potential benefits of laparoscopic aorto-bifemoral bypass surgery. Acta Chir Belg. 2005;105(6): 610-615.

71. Fourneau I, Marien I, Remy P, et al. Conversion during laparoscopic aortobifemoral bypass: a failure? Eur JVasc Endovasc Surg. 2010;39(2): 239-245.
72.Kazmi SS, Jorgensen JJ, Sundhagen JO, et al. A comparative cohort study of totally laparoscopic and open aortobifemoral bypass for the treatment of advanced atherosclerosis. Vasc Health Risk Manag. 2015;11:541-547.

73. Ricco JB, Cau J, Biancari F, et al. Outcome after open and laparoscopic aortic surgery in matched cohorts using propensity score matching. Eur J Vasc Endovasc Surg. 2016;52(2):179-188.

74. Norgren L, Hiatt WR, Dormandy JA, Nehler MR, Harris KA, Fowkes FG. Inter-society consensus for the management of peripheral arterial disease (TASC II). J Vasc Surg. 2007;33(1):S1-S75.

75. Khan NA, Quan H, Bugar JM, Lemaire JB, Brant R, Ghali WA. Association of postoperative complications with hospital costs and length of stay in a tertiary care center. J Gen Intern Med. 2006;21(2):177-180.

76. Bower WF, Jin L, Underwood MJ, Lam YH, Lai PB. Peri-operative blood transfusion increases length of hospital stay and number of postoperative complications in non-cardiac surgical patients. Hong Kong Med J. 2010;16(2):116-120.

77. Zand B, Frumovitz M, Jofre MF, et al. Risk factors for prolonged hospitalization after gynecologic laparoscopic surgery. Gynecol Oncol. 2012; 126(3):428-431.

78. de Vries SO, Hunink MG. Results of aortic bifurcation grafts for aortoiliac occlusive disease: a meta-analysis. JVasc Surg. 1997;26(4):558-569.

79.Jaakkola P, Hippelainen M, Oksala I. Infrarenalaortofemoral bypass surgery: risk factors and mortality in 330 patients with abdominal aortic aneurysm or aortoiliac occlusive disease. Ann Chir Gynaecol. 1996;85(1):28-35.

80. Rosenbaum PR, Rubin DB. The central role of the propensity score in observational studies for causal effects. Biometrika.1983;70(1):41-55.

81. Austin PC. A critical appraisal of propensity-score matching in the medical literature between 1996 and 2003. Stat Med. 2008;27(12):2037-2049.

82. Kunz R, Burnand B, Schunemann HJ; Grading of Recommendations, Assessment, Development and Evaluation (GRADE) Working Group. Das GRADE-System. Ein internationaler Ansatz zur Vereinheitlichung der Graduierung von Evidenz und Empfehlungen in Leitlinien. [The GRADE System. An international approach to standardize the graduation of evidence and recommendations in guidelines]. Internist (Berl). 2008;49(6):673-680.German.

83. Brozek JL, Akl EA, Compalati E, et al. Grading quality of evidence and strength of recommendations in clinical practice guidelines part 3 of 3. The GRADE approach to developing recommendations. Allergy. 2011;66(5):588-595. 


\section{Supplementary material}

\section{Complete search strategy}

\begin{tabular}{|c|c|}
\hline \multicolumn{2}{|c|}{ Cochrane library } \\
\hline & Search \\
\hline $\mathrm{I}$ & laparoscop* or peritoneoscop* or celioscop* or coelioscop*:ti,ab,kw \\
\hline 2 & aort* or iliac* or arter*:ti \\
\hline 3 & $\# 1$ and \#2 \\
\hline \multicolumn{2}{|c|}{ OVID MEDLINE(R) In-process \&other non-indexed citations and OVID MEDLINE(R) 1946 to present } \\
\hline & Search \\
\hline 1 & laparoscopy/or hand-assisted laparoscopy/ \\
\hline 2 & Laparoscopes/ \\
\hline 3 & (laparoscop* or peritoneoscop* or celioscop* or coelioscop*).ti,ab. \\
\hline 4 & Aorta/su(Surgery) \\
\hline 5 & Aorta, abdominal/su(Surgery) \\
\hline 6 & Femoral artery/su(Surgery) \\
\hline 7 & Iliac artery/su(Surgery) \\
\hline 8 & Aortic diseases/su(Surgery) \\
\hline 9 & Aortic aneurysm/su(Surgery) \\
\hline 10 & Aortic aneurysm, abdominal/su(Surgery) \\
\hline 11 & Aortic rupture/su(Surgery) \\
\hline 12 & Iliac aneurysm/su(Surgery) \\
\hline 13 & Lerichesyndrome/su(Surgery) \\
\hline 14 & Arterial occlusive diseases/su(Surgery) \\
\hline 15 & Arteriosclerosis/su(Surgery) \\
\hline 16 & Arteriolosclerosis/su(Surgery) \\
\hline 17 & Arteriosclerosis Obliterans/su(Surgery) \\
\hline 18 & Atherosclerosis/su(Surgery) \\
\hline 19 & Peripheral arterial disease/su(Surgery) \\
\hline 20 & Intermittent claudication/su(Surgery) \\
\hline 21 & (aort* adj4 (surg* or operat* or bypass* or revasc*)).ti,ab. \\
\hline 22 & or/l-3 \\
\hline 23 & or/4-21 \\
\hline 24 & 22 and 23 \\
\hline 25 & limit 24 to year="I990 -Current" \\
\hline
\end{tabular}

\begin{tabular}{ll}
\hline Embase I 980 to today & \\
\hline 1 & Search \\
2 & laparoscopy/or hand assisted laparoscopy/or laparoendoscopic single site surgery/or laparoscopic surgery/ \\
3 & Aorta/su(Surgery) \\
4 & Abdominal aorta/su(Surgery) \\
5 & Femoral artery/su(Surgery) \\
6 & lliac artery/su(Surgery) \\
7 & Aorta disease/su(Surgery) \\
8 & Exp aorta aneurysm/su(Surgery) \\
9 & Aorta atherosclerosis/su(Surgery) \\
10 & Exp aorta constriction/su(Surgery) \\
11 & Aorta occlusion/su(Surgery) \\
12 & Exp aorta stenosis/su(Surgery) \\
13 & Leriche syndrome/su(Surgery) \\
14 & Peripheral occlusive artery disease/su(Surgery) \\
15 & Exp artery occlusion/su(Surgery) \\
16 & Exp claudication/su(Surgery) \\
17 & or/2-15 \\
18 & I and I6 \\
\hline
\end{tabular}


PubMed

Search to find articles not yet published in medline

Search

I (laparoscop*[ti] AND (aortic*[ti] or aorta[ti] OR vascular[ti])) not medline[sb]

Vascular Health and Risk Management is an international, peerreviewed journal of therapeutics and risk management, focusing on concise rapid reporting of clinical studies on the processes involved in the maintenance of vascular health; the monitoring, prevention and treatment of vascular disease and its sequelae; and the involvement of metabolic disorders, particularly diabetes. This journal is indexed on PubMed Central and MedLine. The manuscript management system is completely online and includes a very quick and fair peer-review system, which is all easy to use. Visit http://www.dovepress.com/ testimonials.php to read real quotes from published authors. 